\title{
A crise da psiquiatria centrada no diagnóstico e o futuro da clínica psiquiátrica: psicopatologia, antropologia médica e o sujeito da psicanálise
}

\section{| ${ }^{1}$ Mario Eduardo Costa Pereira |}

Resumo: O avanço da psiquiatria contemporânea pelas vias da biomedicina conduziu à impressão de que a psicopatologia, enquanto ciência do padecimento humano em suas diferentes dimensões, teria se tornado obsoleta. Uma nosologia psiquiátrica construída em bases exclusivamente biológicas e experimentais tomaria seu lugar, fundando definitivamente a psiquiatria como especialidade médica de pleno direito. $\mathrm{O}$ presente artigo examina os impasses desse projeto de redução do psicopatológico ao nosológico e aponta algumas pistas pelas quais a teorização psicanalítica do sujeito e de seu pathos poderia fornecer as bases antropológicas para a fundação de uma psicopatologia apta a sustentar a clínica psiquiátrica.

> Palavras-chave: psicopatologia; nosografia psiquiátrica; antropologia médica.
1 Departamento de Psicologia Médica e Psiquiatria, Universidade Estadual de Campinas. Campinas-SP, Brasil. Endereço eletrônico: marioecpereira@uol.com.br

Recebido em: 01/08/2014 Aprovado em: 24/11/2014 
O objetivo deste trabalho é propor um exame teórico e crítico das relações entre diagnóstico e clínica psiquiátrica no contexto contemporâneo. Seu pano de fundo é o esforço para a atualização do debate sobre os fundamentos antropológicos e psicopatológicos da prática psiquiátrica. Nossa hipótese geral, que no presente artigo será necessariamente apenas esboçada, é a de que uma releitura da psicopatologia a partir da noção de sujeito, tal como decorrente da abordagem lacaniana da obra de Freud, permitiria superar alguns dos principais impasses teóricos e clínicos atuais nesse campo.

Para isso, será tomado como ponto de partida aquilo que chamaremos de "crise contemporânea da psiquiatria centrada no diagnóstico operacional" (rule-based descriptive diagnosis), tornada patente pela recente confrontação entre as duas concepções hegemônicas referentes ao estatuto epistemológico do diagnóstico. Por um lado, coloca-se a perspectiva pragmática que tem no DSM5, da American Psychiatric Association (APA), sua referência maior. Por outro, a posição mais estritamente naturalista sustentada pelo National Institute of Mental Health dos Estados Unidos, materializando-se sob a forma do Research Domain Criteria (RDoC).

Serão examinados os principais pontos de tensão opondo essas duas perspectivas. Em seguida, discutiremos o fato de que, apesar das profundas diferenças que as separam, ambas desembocam em uma prática clínica centrada no diagnóstico de entidades mórbidas - distintas ou dimensionais - do qual decorrem, de maneira quase automática, uma árvore de decisões técnicas e terapêuticas preestabelecidas, sem que a dimensão da singularidade e a escuta do paciente em sua dimensão específica de sujeito desempenhem de fato algum papel efetivo na compreensão e no manejo do fenômeno psicopatológico enquanto tal.

Por fim, indicaremos os possíveis progressos teóricos, éticos e clínicos decorrentes da introdução da problemática do sujeito, tal como definida na psicanálise lacaniana, na elaboração da psicopatologia necessária para fundamentar a clínica psiquiátrica contemporânea. Nossa proposta é que tal perspectiva psicanalítica é capaz de fundamentar uma antropologia médica mais apropriada para a psiquiatria. O presente artigo, de caráter claramente programático, terá atingido seus objetivos se puder suscitar novas perspectivas de 
interação entre psiquiatria e psicanálise no campo da psicopatologia e da clínica

psiquiátrica de nossos tempos.

\section{A crise do diagnóstico e o diagnóstico da crise}

De forma surpreendente, a publicação do DSM-5, em maio de 2013, longe de ter constituído um triunfo das convenções diagnósticas sistematizadas em psiquiatria, terminou, na verdade, por expor uma fratura epistemológica fundamental nessa disciplina. Ao desautorizar publicamente - e às vésperas do lançamento de sua mais recente edição - a abordagem nosográfica do DSM, Thomas Insel, presidente do National Institute of Mental Health (NIMH) dos Estados Unidos, coloca o dedo na ferida teórica da abordagem diagnóstica que permitira, desde os anos oitenta, certa legitimidade às pretensões da psiquiatria de ser reconhecida como especialidade médica de pleno direito. Zorzanelli, Dalgalarrondo e Banzato (2014, p. 329) expõem muito claramente os termos do conflito:

Segundo Insel, as categorias diagnósticas do DSM, baseadas em conjuntos de sintomas clínicos e não em medidas laboratoriais objetivas (como em outras áreas da medicina), não teriam validade científica. É preciso esclarecer que o sentido de validade adotado por Insel é o de uma inscrição biológica definida, dada sua suposição de que: 'mental disorders are biological disorders involving brain circuits that implicate specific domains of cognition, emotion, or behavior' (INSEL, 2013).

Consequentemente, a pesquisa psiquiátrica deveria, ainda segundo Insel, orientar-se na busca de verdadeiros “marcadores biológicos”, específicos para cada um dos diferentes transtornos mentais. Dessa forma, a abordagem nosográfica pragmática do DSM, fundamentada no estabelecimento de critérios diagnósticos convencionais e explícitos, formalmente delimitados e diretamente acessíveis (através do relato do paciente, da observação clínica de determinados sinais e sintomas e dos diferentes tipos de evolução) seria insuficiente para as pretensões naturalistas de uma psiquiatria realmente "médica". $\mathrm{Na}$ visão do presidente do NIMH, o DSM teria tido sucesso no sentido de conferir confiabilidade ao diagnóstico psiquiátrico. Esse sistema teria fracassado, contudo, e de maneira superlativa, em estabelecer a validade biológica das entidades mórbidas das quais a psiquiatria deveria se ocupar.

Dessa forma, o antagonismo entre essas duas posições expõe, a partir do próprio mainstream psiquiátrico, a insuficiência do DSM para inscrever as categorias 
diagnósticas que descreve no prestigioso campo da racionalidade biomédica, fundamental para o reconhecimento de uma especialidade em seu pertencimento ao campo da medicina atual. Nessa mesma lógica, o discurso de Insel apresenta a oncologia como uma espécie de ideal a ser alcançado pela psiquiatria: as doenças das quais se ocupa uma especialidade médica contemporânea devem ser claramente delimitadas em termos de patologia biológica, com uma história natural típica, evolução previsível, uma etiologia positiva descrita em termos da biologia, ou seja, através de marcadores biológicos capazes de estabelecer um grau elevado de certeza diagnóstica e de orientar o prognóstico, bem como as melhores abordagens terapêuticas.

O DSM, até então considerado o grande responsável e guardião do prestígio da psiquiatria como especialidade médica, passa a ser visto como instrumento diagnóstico precário e provisório, assentado em bases clínicas empíricas e meramente convencionais, aguardando os progressos das ciências biológicas aplicadas aos transtornos mentais para ceder seu lugar a uma nova nosografia, dessa vez biologicamente mais consistente.

A aposta é alta - Claudio Banzato já havia empregado a feliz expressão "bet on pathophysiology" para descrever a esperança e a promessa sempre renovadas, mas nunca cumpridas, de que um dia a psiquiatria seria capaz de descrever suas entidades mórbidas em termos exclusivamente fisiopatológicos (BANZATO, 2004). E os riscos de tal aposta, agora renovada até o seu paroxismo pelo NIMH, são ainda maiores, pois agregam vários elementos fortemente perturbadores da legitimidade do pertencimento da psiquiatria ao campo da biomedicina. Entre eles, podemos destacar o fato de que esse ponto de vista desqualifica epistemologicamente a abordagem pragmática do DSM, sem ter ainda colocado no seu lugar nenhum outro sistema efetivamente válido do ponto de vista biomédico.

Desde 2009, o NIMH desenvolve uma estratégia "for the development, for research purposes, of new ways of classifying psychopathology based on dimensions of observable behavior and neurobiological measures" (NIMH, site). O RDoC, Research Domain Criteria, foi assim lançado para implementar essa estratégia. Seu esforço é "to define basic dimensions of functioning (such as fear circuitry or working memory) to be studied across multiple units of analysis, from genes to neural circuits to behaviors, cutting across disorders as traditionally defined" (NIMH, site) 
Reitera-se aqui, portanto, que o nível de descrição cientificamente legítimo para os fenômenos psicopatológicos é o das neurociências e da genética psiquiátrica.

Tal esforço encontra-se em curso e, em sua forma e conteúdo atuais, pode-se dizer que sua aposta permanece em estado de promessa e de intensões. A aposta patofisiológica a ser consolidada - agora de uma vez por todas - através dessa nova abordagem estritamente naturalista dos transtornos mentais, não desqualifica a ideia de que a psiquiatria opera fundamentalmente baseada no diagnóstico de entidades mórbidas distintas, ainda que comportando transições entre elas. Sua crítica repousa na insuficiência dos critérios clínicos e baseados em convenções diagnósticas para determinação da especificidade biológica das "doenças" próprias ao campo psiquiátrico. Em última instância, espera-se dos progressos científicos da psiquiatria, que esta disciplina venha a realizar o repatriamento das "mental disorders" ao registro mais claramente biomédico das "mental diseases". Em outros termos, esse ponto de vista considera que a abordagem fundamental para se credenciar a psiquiatria como especialidade médica de pleno direito seria a nosologia e não a psicopatologia.

\section{A psiquiatria centrada no diagnóstico das entidades mórbidas}

Georges Canguilhem sustentava resolutamente que a medicina não era por si própria uma ciência, mas um campo de práxis, da technè dos gregos, da ars dos latinos. Trata-se, pois, de uma prática do cuidado fundamentada em ciência, mas a esta irredutível. Ele propõe, já no início de seu grande clássico, $O$ normal e o patológico (CANGUILHEM, 1966), que para agir é necessário localizar e delimitar. Mas recorda igualmente que foi a consolidação dessa perspectiva prática que levou à sedimentação cultural de uma concepção ontológica da doença. É essa visão, que tem nas moléstias infecciosas seu paradigma maior, que concebe uma separação radical entre a doença e o doente, aquela sendo vista como o resultado de um ataque provindo de um agente exterior ao sujeito, reduzido aqui à condição de vítima e de paciente.

Jacques Schotte (FEYS, 2006) recorda que até meados do século XVIII soaria muito estranho a um médico europeu que seu ofício fosse descrito como sendo uma prática centrada no diagnóstico de uma doença concebida como uma 
entidade exterior ao indivíduo em sua eliminação técnica. Fortemente marcada por suas raízes na medicina hipocrática e na teoria dos humores, a atividade médica era fundada na identificação dos desequilíbrios e desarmonias na vida do paciente, de modo que o foco do tratamento residia na instauração de medidas capazes de restituir o equilíbrio e a potência autorregenerativa do corpo.

A figura de Thomas Sydenham, com sua Synopsis Nosologiae Methodicae de 1769, permanecerá como uma espécie de divisor simbólico de águas, instaurando um novo "estilo de pensamento" na medicina, segundo a terminologia posteriormente consagrada por Ludwig Fleck (1979). Doravante a nosologia passaria a conceber a "doença" como entidade autônoma, independente do sujeito que dela padece, encarnando um mal exterior e com determinaçôes próprias. Os médicos e a cultura em geral tenderiam, a partir da generalização dessa concepção de nosologia, a representar o adoecimento em termos de padecimento de uma doença que se apodera, enquanto potência exterior autônoma, do organismo do paciente.

Surgida na passagem do século XVIII para o século XIX, a psiquiatria contemporânea foi inteiramente gestada na vigência desse estilo de pensamento. Muito precocemente em sua história, a nascente psiquiatria se apressava a delimitar clinicamente e com a maior precisão descritiva possível "as espécies do gênero loucura" (PESSOTTI, 1994), na esperança de lançar as bases para a elaboração futura de uma verdadeira nosologia, estabelecida em bases positivas e biológicas. A "aposta na patofisiologia" se expressa desde os primeiros passos da nova especialidade e encontrará nas figuras de Falret, Griesinger e de Kraepelin alguns de seus principais expoentes. Mesmo Freud, em alguns momentos de sua obra, expressou a convicção de que um dia diversos conceitos de sua teoria, que até aquele momento somente podiam ser formulados na linguagem heurística própria a sua metapsicologia, seriam um dia traduzidos na linguagem objetiva das ciências naturais. Contudo, sua obra foi uma das que contribuíram mais decisivamente para que se pudesse conceber a psicopatologia de maneira autônoma em relação às ciências naturais e que essa pudesse fundamentar uma prática clínica enquanto tal no campo da psiquiatria.

No contexto da psiquiatria contemporânea, em que as posições pragmáticas e naturalistas expõem publicamente seus conflitos e tensões, ambas compartilham resolutamente um elemento permanece estável e fixo, apesar das diferenças que 
as separam. Para ambas, a prática psiquiátrica tem como elemento central o

diagnóstico da entidade mórbida especifica, seja ela concebida como transtorno, seja como doença mental. Além disso, ambas compartilham a firme convicção da aposta na patofisiologia: um dia serão reunidos conhecimentos biológicos suficientes para demonstrar de maneira inequívoca a doença física que se expressa no campo mental, de maneira análoga, em seu procedimento científico, ao que é feito nas demais especialidades médicas. Toda a questão repousa, pois, em saber se um fenômeno psicopatológico encontra seu nível descritivo adequado no jogo de linguagem das ciências naturais.

Descortina-se assim o fato de que as dificuldades com as quais se confronta tal abordagem naturalista dos transtornos mentais não se restringem à incompletude dos conhecimentos biológicos necessários para sustentar tal projeto. No limite, sempre se pode recorrer às esperanças no futuro da ciência: um dia teremos os dados e modelos biológicos que nos faltam hoje para fundamentar uma nosografia psiquiátrica de pleno direito. Entretanto, existem obstáculos de outras ordens, irredutíveis à suposta insuficiência provisória de conhecimentos científicos sobre as chamadas "doenças mentais".

Um deles, de natureza epistemológica, interroga as próprias condições de possibilidade de se fazer a descrição de um fato de natureza psicopatológica através de uma linguagem estritamente biológica, reduzindo-o à categoria biomédica de "doença". No campo psiquiátrico, isso implica relançar-se antigas aporias ligadas - e tanto denunciadas - ao conceito de "doença mental". Uma delas ressalta imediatamente: ao se elaborar uma nosografia psiquiátrica segundo um jogo de linguagem exclusivamente biomédico, sem se recorrer a qualquer registro da subjetividade do paciente, nem à contextualização linguística e históricocultural das manifestações clínicas, não se estaria descartando justamente o plano psicopatológico do padecimento psíquico?

Para termos uma ideia do tipo de aporia ao qual pode conduzir esse tipo de aposta epistemológica, tomemos um exemplo simples, mas contundente. Consideremos que não exista qualquer contestação da hipótese da participação decisiva de predisposições genéticas no chamado transtorno de déficit de atenção e hiperatividade e que, dessa forma, esse seja um ponto consensual. Consideremos, então, que tal constituição hereditária possa ser descrita integralmente em suas conexões com o quadro clínico que dela decorreria. Ainda 
assim, o comportamento "sintomático" observado, o "déficit de atenção", só teria uma conotação patológica em uma cultura e em um momento histórico em que a "concentração" precoce nas atividades escolares, por exemplo, seja conotada positivamente. Em outra configuração cultural, menos preocupada com o "desempenho" e com a "performance escolar", na qual se valorizasse a dispersão e a experimentação intelectual inconsequente, os mesmos genes hoje considerados "mórbidos" seriam, nessa outra cultura, tidos como genes de proteção contra o risco de que as crianças participassem de maneira excessivamente séria e precoce a uma educação centrada na obtenção de competências práticas e na disputa pelos melhores desempenhos. Em outros termos, ao se passar do campo da descrição biológica para o registro especificamente psicopatológico, ocorre um salto categorial que impede a redução direta da psicopatologia à alteração biológica supostamente mórbida da função. Vemos, assim, que a mera constatação científica do tipo de ação de um determinado componente genético não constitui por si só o plano propriamente psicopatológico de suas manifestações observáveis. Impõese, portanto, uma questão preliminar a toda teorização possível do estatuto das neurociências e da genética psiquiátrica no campo da psiquiatria. Essa questão é a da especificidade epistemológica do campo psicopatológico em relação à nosografia e à nosologia psiquiátricas. Somente a partir daí é que poderemos situar de maneira rigorosa as relações entre psicopatologia e clínica psiquiátrica.

\section{Psicopatologia e psiquiatria}

O elemento central a ser discriminado para esse debate é, portanto, o sentido teórico a se atribuir ao termo "psicopatologia", uma vez que este transcende qualquer tentativa de redução a uma semiologia psiquiátrica ou a uma abordagem explicativa da "doença mental". Pelo contrário: é a própria noção de "doença mental" que necessita ser elucidada pela psicopatologia.

Recente editorial do British Journal of Psychiatry, publicado em setembro de 2014 e assinado por Giovanni Stanghellini e Matthew R. Broome, expõe os termos dessa questão:

Biomedical science was in part built upon the transformation of a complaint into a symptom. This allowed medical science to see in a complaint (e.g. exhaustion) the effect of a pathological cause active in the human body (e.g. an endocrine dysfunction).

This move from complaint to symptom to pathophysiology may overshadow the fact that a complaint has a meaning for the individual sufferer: it expresses a question or 
desire. A person may not necessarily seek elimination of his complaint, but rather ful-

fillment of his desire (e.g. to see the doctor fail and himself triumphantly to become an incurable patient). (STANGHELLINI; BROOME, 2014).

O título desse importante editorial é justamente "Psychopathology as the basic science of psychiatry". O argumento nele apresentado vai bem além de situar a necessidade de uma contextualização histórica e antropológica de determinada manifestação psíquica para tornar inteligível seu caráter especificamente psicopatológico. Ele destaca de maneira precisa a dimensão subjetiva e singular da inscrição do sintoma na vida desiderativa do sujeito. Aqui é interessante observar a emergência espontânea no argumento desses autores de categorias propriamente psicanalíticas visando dar conta da especificidade do campo psicopatológico, tais como a diferenciação entre demanda e desejo, o caráter paradoxal de realização de desejo embutido no sintoma, bem como o surgimento de um gozo paradoxal, de natureza autodestrutiva, sustentado na relação transferencial com médico. São esses elementos que outorgam o caráter propriamente psicopatológico à condição apresentada pelo paciente. Todos eles são identificáveis no interior da situação clínica concreta, mas irredutíveis às abordagens objetivantes e generalizantes próprias às ciências naturais. Uma determinada condição é psicopatológica de maneira absolutamente singular àquele sujeito específico, não sendo generalizável enquanto tal.

Ora, tal abordagem proposta pelos autores desse editorial é profundamente relevante, dado o contexto contemporâneo de uma psiquiatria ávida por reconhecimento em sua legitimidade biomédica, mas esquecida da dimensão propriamente humana de seu campo. Contudo, ela não é de forma alguma original, inscrevendo-se na esteira de uma longa tradição do pensamento psicopatológico. Basta evocarmos o fato de que Karl Jaspers (1979) sustentava a irredutibilidade da psicopatologia ao campo médico ou mesmo da psiquiatria, devendo constituir uma disciplina autônoma, dispondo de seus próprios métodos. Binswanger, em sua famosa conferência intitulada "Sobre a fenomenologia", de 1927, criticava duramente o equívoco que consistiria em se abordar o fato psicopatológico através dos métodos objetivantes próprios às ciências naturais. Sendo um fato humano e subjetivo por excelência, a psicopatologia deveria dispor de métodos próprios para alcançar a subjetividade efetiva de cada paciente. Tal como propunha Henri Maldiney, ao imergirmos um fato humano nas grades de leitura das ciências 
naturais, o que produzimos é um objeto, perdendo-se justamente a especificidade humana nessa operação (MALDINEY, 1991).

É assim que Binswanger colocaria, portanto, o problema dos fundamentos específicos da psicopatologia - toda psicopatologia começa pela questão: "o que é o homem?” Nessa perspectiva, contrariamente às expectativas biomédicas de que a psicopatologia pudesse ser formulada em uma linguagem estritamente naturalista, o que se delineia no horizonte teórico da psiquiatria é a urgência da delimitação de uma antropologia médica, capaz de sustentar o fato psicopatológico como fenômeno propriamente humano, marcado pela linguagem, pela sexualidade e pela consciência da própria finitude.

Uma longa tradição de interrogações médicas e psicopatológicas se desenvolveu a partir da concepção de sujeito decorrente da experiência psicanalítica. Groddeck, Ferenczi, Binswanger, Viktor von Weizsaecker, Jacques Schotte, Pierre Fédida, Henri Maldiney, entre muitos outros, foram autores destacados no projeto de prover a psicopatologia de uma antropologia médica ancorada na psicanálise e em sua concepção de sujeito.

Von Weizsaecker, em particular, é considerado como o pioneiro na teorização de uma antropologia médica. Em seu famoso livro $O$ círculo da estrutura (Der Gestaltkreis), traduzido em 1958 para o francês por Michel Foucault, mostra bem a necessidade, para se fundar uma abordagem especificamente humana do patológico de que trata a medicina, de se repensar a própria biologia em termos da vida enquanto tal, sem reduzi-la a seus supostos elementos inorgânicos constitutivos:

Para estudar o vivo, é necessário tomar parte da vida. Por certo, pode-se tentar derivar
o vivo do não-vivo, mas esse esforço até aqui sempre fracassou. Pode-se também ten-
tar renegar sua própria vida na ciência, mas é enganar a si mesmo em segredo. A vida,
enquanto vivos, nós a encontramos aí bem perto; ela não surge de forma alguma, mas
ela já está aí, ela não começa, pois ela já começou. Não encontramos no começo de
nenhuma ciência da vida o começo da própria vida, ao contrário, a ciência começou
pelo despertar da interrogação em plena vida. (VON WEIZSAECKER, 1958, p. 33).

Coloca-se assim uma questão fundamental para o cientista que se ocupa da patologia mental: é possível colocar-se em um lugar de neutralidade apática para se tratar do pathos? Que teoria do pathos é compatível com o fato que o pathos do próprio pesquisador está envolvido na elaboração do objeto teórico e clínico do qual ele pretende dar conta? Desenvolvida em um diálogo constante com o pensamento de Freud, a obra de Von Weizsaecker lança-se ao esforço de 
criar um substrato teórico biológico para a medicina, que levasse em conta a especificidade da vida em si e da vida do homem, enquanto tal. De certa maneira, a psicopatologia, tal como concebida por Freud, deveria possuir esse mesmo rigor antropológico para fundamentar uma prática psiquiátrica.

\section{Freud, Lacan e a psiquiatria}

Pode-se descrever a posição de Freud face às relações entre psicanálise e psiquiatria como sendo propriamente ambivalente. Em sua Conferência Introdutória 16, de 1917, por exemplo, sobre psicanálise e psiquiatria, Freud considerava que seria possível uma relação de colaboração fecunda entre esses dois campos. Mais do que isso, em uma famosa analogia, o médico vienense anteciparia esse papel referencial da psicanálise para a constituição do substrato psicopatológico necessário à psiquiatria: a psicanálise estaria para a psiquiatria na mesma posição que a histologia estaria em relação à anatomia. Uma e outra forneceriam as bases íntimas e efetivas de fenômenos que só se tornariam visíveis em um plano mais exterior e sistêmico.

Contudo, Freud foi progressivamente exprimindo a necessidade de se conceber as duas disciplinas em suas próprias especificidades e de impedir que a psicanálise fosse absorvida em uma posição de vassalagem em relação aos ideais higienistas e adaptativos da crescente psiquiatria norte-americana de seu tempo. Tais inquietações terminaram por se revelar agudamente premonitórias. A psicanálise poderia, segundo Freud, fornecer o substrato psicopatológico necessário à psiquiatria, à condição de não se deixar reduzir a uma posição de mero complemento terapêutico, destinado a fornecer o complemento psicológico necessário para ocluir as falhas da concepção psiquiátrica dos transtornos mentais e de seus tratamentos.

Lacan, por sua vez, jamais tratou de maneira sistemática seus pontos de vista relativos à medicina e à psiquiatria a partir da perspectiva psicanalítica. Contudo, deixou amplas pistas que permitem um delineamento bastante útil e preciso das consequências de seu ensino para uma fundamentação psicanalítica do campo psicopatológico.

Em sua intervenção de 1966, sobre "O lugar da psicanálise na medicina", Lacan sustenta a ideia de que em nossos tempos de biomedicina, a psicanálise se constitui com a herdeira da tradição clínica da medicina. A própria noção 
médica por excelência de "anamnese" refere-se desde suas raízes hipocráticas ao processo pelo qual o médico, ao dar a palavra ao paciente para falar de seu padecimento, termine por superar o esquecimento e lembrar-se do que, de fato, lhe ocorreu. A psicanálise não seria possível, portanto, sem essa herança clínica resgatada da medicina.

Além disso, Lacan destaca duas contribuiçōes decisivas que a psicanálise teria a oferecer para o campo específico da clínica médica: auxiliar o médico a compreender que nem sempre o paciente deseja de fato aquilo que demandou. O desejo é sempre de outra coisa e, em última instância, todo pedido é um pedido de amor. Por outro lado, o conceito de gozo permitiria ao médico conceber, a partir de outra perspectiva, os fenômenos eróticos que se manifestam no corpo, frequentemente em contradição com a saúde, com o bom-senso, com a própria sobrevivência. Na medicina, encontra-se um campo privilegiado para a emergência para aquilo que está além do princípio do prazer. Demanda, desejo e gozo: justamente os elementos implicitamente evocados no editorial do BJP acima mencionado.

Como se sabe, Freud e Lacan legaram em suas obras teóricas os elementos de uma antropologia de inspiração psicanalítica capaz de fundar uma psicopatologia do sujeito singular, utilizável em uma prática psiquiátrica. Nesse caso, não se trata de exigir do psiquiatra uma formação ou uma prática analíticas no sentido estrito, mas que este possa conceber sua ação junto ao paciente de maneira sensível às emergências do sujeito do inconsciente e a seus impasses subjetivos expressos nas queixas, sintomas e passagens ao ato.

O futuro do movimento psicanalítico e do percurso contemporâneo da própria psiquiatria mostraram os esforços de inúmeros autores buscando efetivar esse imenso legado teórico sob a forma de uma releitura completa do campo da psicopatologia a partir das categorias psicanalíticas. Por outro lado, no campo especificamente psiquiátrico, as abordagens biomédicas, neurocientíficas, genéticas e psicofarmacológicas conduziram a um certo eclipse da problematização propriamente psicopatológica da clínica psiquiátrica. A psicopatologia poderia parecer ter chegado a seu ocaso, permanecendo apenas como resquício histórico de tempos superados, nos quais a psiquiatria não conseguia ainda se expressar em linguagem francamente científica, ou seja, objetiva e experimental.

Os impasses na teoria nosológica dos fenômenos mórbidos mentais e na própria clínica psiquiátrica terminariam por mostrar que a tarefa da fundamentação 
antropológica da psicopatologia foi apenas adiada. Não superada. Vejamos um exemplo contemporâneo.

\section{O exemplo dos impasses da "harmful dysfunction analysis"}

Conhece-se bem a importância maior que as teorias de Jerome Wakefield relativas ao conceito de "harmful dysfunction analysis" tiveram na constituição do background teórico do DSM-5 (WAKEFIELD, 1992). Segundo essa teoria, a noção de transtorno mental (mental disorder) só poderia ser legitimamente empregada se uma condição psíquica respondesse a duas exigências. A primeira seria de caráter objetivo e factual: haveria uma alteração da função mental que, segundo o autor, teria sido selecionada pela seleção natural como a mais eficiente para a sobrevivência da espécie. Em outros termos, a noção de dysfunction garantiria a ancoragem do conceito de mental disorder em um terreno de ciências naturais. $\mathrm{O}$ segundo elemento teria uma dimensão valorativa e contextual: a alteração decorrente dessa disfunção deveria ser subjetiva e socialmente apreciada como prejudicial ao indivíduo. Vemos assim articulados fatos objetiváveis e valores humanos em um único conceito. Essa famosa concepção híbrida do transtorno mental constituiria a base para a legitimidade médica e social das nosologia e da nosografia psiquiátricas.

Contudo, um argumento crítico maior se impõe imediatamente à posição de Wakefield: a introdução da um elemento valorativo na definição de transtorno mental, ainda que apoiado na contestável ideia de alteração da função mental selecionada pela seleção natural, ${ }^{1}$ atestaria por si só que uma descrição exclusivamente biológica das categorias nosológicas com que opera a psiquiatria seria radicalmente insustentável. Uma vez presente o elemento valorativo, é a própria ambição de uma descrição exclusivamente naturalista do fato psicopatológico que se demonstra impossível.

Dito em outras palavras, pode-se conceber que todo progresso nos conhecimentos neurobiológicos relativos aos padecimentos psíquicos são necessários e indispensáveis. Mas não decorre necessariamente daí que esses mesmos conhecimentos tornariam obsoleta a psicopatologia enquanto disciplina fundante da psiquiatria enquanto especialidade médica.

A tensão teórica instaurada por essa perspectiva é tão profunda e radical que termina por colocar em questão o conjunto da medicina. Nesse caso, como 
sugere Fulford (2001, 2004, 2006), a psiquiatria não estaria em uma posição de fraqueza teórica em relação às demais especialidades médicas por não definir suas categorias mórbidas em termos exclusivamente biológicos. Ao contrário, a psiquiatria seria a especialidade médica em que a irredutibilidade do patológico ao nosológico se expressa mais claramente e coloca-se à medicina em geral a urgência de teorizar o patológico, enquanto fenômeno propriamente humano, para além da biologia. É apenas desse esforço que se pode esperar uma verdadeira especificação da medicina enquanto práxis no campo patológico, irredutível à mera aplicação direta das chamadas "ciências médicas".

\section{Das "ciências médicas" à Ars medica}

$\mathrm{Na}$ concepção biomédica da medicina em geral e em psiquiatria, encontramos uma prática organizada a partir do diagnóstico da doença, ou da entidade mórbida pragmaticamente delimitada, que acomete o indivíduo. Todo o resto decorre da inscrição do quadro apresentado pelo paciente como sendo um caso concreto de uma espécie mórbida previamente delimitada e conhecida pela ciência. Uma vez estabelecido o diagnóstico nosológico, toda a prática decorreria do diagnóstico estabelecido em uma relação dedutiva: idealmente, se o diagnóstico é A, então a conduta consensual do ponto de vista da objetividade cientifica seria B.

O fator humano - singular, subjetivo, desiderativo, inconsciente e propriamente erótico - do fato psicopatológico, tal como descrito inicialmente por Freud e posteriormente recuperado na tradição psicopatológica, desequilibra a tranquila exterioridade da "doença mental" em relação a seu suposto hospedeiro. O sujeito não é absolutamente "exterior" a sua psicopatologia, da mesma forma que o médico não pode pretender falar em posição de autoridade absoluta em relação ao pathos de seu paciente.

Tal maneira de conceber os fenômenos psicopatológicos não implica necessariamente dissolver a psiquiatria na psicanálise, nem tampouco considerar que a "psicoterapia" é o destino final de toda a intervenção psiquiátrica. A psiquiatria, enquanto disciplina médica, encontra-se totalmente legitimada para intervir medicamente nas condições psicopatológicas cuja expressão clínica solicite o alívio, a contenção, o limite, a intervenção contra o excesso destrutivo ou inútil - desde que, naturalmente, não o faça no sentido de sufocar ou de ocluir o sujeito, a fantasia, o desejo que emergem de maneira por vezes violenta e 
selvagem pela via do fenômeno psicopatológico. Nesse caso, o tratar psiquiátrico corresponde a reinstaurar as condições nas quais o sujeito possa se colocar radicalmente em questão, ou pelo menos, de se fazer reconhecer enquanto tal. Trata-se, pois, de uma posição ética, com incidências clínicas. Que disso resulte o engajamento em um processo psicanalítico mais sistemático e mais aprofundado, não é algo que decorra diretamente da intervenção psiquiátrica. Mas esta não deve impedir a eventualidade de tal desfecho.

Dessa maneira, guardando sua especificidade médica e sem se dissolver no campo da psicanálise, a psiquiatria pode encontrar no campo psicanalítico os fundamentos antropológicos, ou mais especificamente, uma teoria do sujeito, compatível com os fenômenos psicopatológicos dos quais se ocupa e capaz de sustentar uma intervenção propriamente médica face aos excessos desse sofrimento subjetivo, sem que nesse movimento seja necessário ou inevitável sufocar a emergência do sujeito do interior de seu pathos específicos.

\section{Referências}

BANZATO, C.E.M. Classification in psychiatry: The move towards ICD-11 and DSM-V. Curr Opin Psychiatry, v. 17, p. 497-591, 2004.

BINSWANGER, L. De la phénoménologie. In: Introduction à l'analyse existentielle. Paris: Les Éditions de Minuit, 1971. p. 79-117.

BOORSE, C. A rebuttal on health. In: HUMBER, J.M.; ALMEDER R.F. (Eds.). What is disease? Totowa: Humana Press, 1997. p. 1-134.

. Concepts of health. In: VAN DE VEER, D.; REGAN, T. (Eds.). Health Care Ethics: An Introduction. Philadelphia: Temple UP, 1987. p. 359-393.

. On the distinction between disease and illness. Philosophy and Public Affairs, v. 5, n. 1, p. 49-68, 1975.

. What a theory of mental health should be. Journal Theory Social Behavior, v. 6, p. 61-84, 1976.

CANGUILHEM, G. Ecrits sur la médecine. Paris: Seuil, 2002.

Le normal et le pathologique. Paris: P.U.F., 1966.

ENGEL, G.L. A unified concept of health and disease. Perspectives in Biology and Medicine, v. 3, p. 459-485, 1960.

ENGELHARDT, H.T. Clinical problems and the concept of disease. In: NORDENFELT; LINDAHL, L.B.I.B. (Eds.). Health, disease and casual explanations in medicine. Dordrecht: Reidel, 1984. p. 27-41. 

. Ideology and etiology. Journal of Medicine and philosophy, v. 1, p. 256-268, 1976.

FEYS, J.-L. L'anthropopsychiatrie de Jacques Schotte - une introduction, Paris, Hermann Editeurs, 2009.

FLECK, L. Genesis and development of a scientific fact. Chicago and London, The University of Chicago Press, 1979.

FREUD, S. Conferências introdutórias à psicanálise. Conferência XVI : Psicanálise e psiquiatria. In: Obras Psicológicas Completas de Sigmund Freud, v. XVI, Rio de Janeiro : Imago, [1917] 1976.

FIRST, M. et al. Clinical utility as a criterion for revising psychiatry diagnoses. American Journal of Psychiatry, v. 161, n. 6, p. 946-54, Jun. 2004.

FULFORD, K.W.M. "What is (mental) disease?": an open letter to Christopher Boorse. J Med Ethics., v. 27, p. 80-85, 2001.

FULFORD, B. et al. Nature and narrative: an introduction to the new philosophy of psychiatry. Oxford: Oxford University Press, 2004.

FUlfORD, K.; THORNTON, T.; GRAHAM G. Oxford Textbook of Philosophy and Psychiatry. Oxford: Oxford University Press, 2006.

HYMAN, S.E. Neuroscience, genetics and the future of psychiatric diagnosis. Psychopathology, v. 35, p. 139-44, 2002.

HOFMANN, B. On the triad disease, illness and sickness. The Journal of Medicine and Philosophy, v. 27, p. 651-673, 2002.

INSEL, T. Research Domain Criteria (RDoC): towards a new classification framework for research on mental disorders. American Journal of Psychiatry, v. 167, n. 7, p. 748-751, July 2010. INSEL, T. NIMH Director's Blog: Tranforming Diagnosis. Dsponível em: <http://www. nimh.nih.gov/about/director/2013/transforming-diagnosis.shtml>. Acesso em: 29 abr. 2013. JASPERS, K., Psicopatologia Geral. Rio de Janeiro: Atheneu,1979.

KENDELL, R.E. The concept of disease and its implications for psychiatry. The British Journal of Psychiatry, v. 127, p. 305-315, 1975.

KENDLER, K.S. Toward a philosophical structure for psychiatry. Am J Psychiatry, v. 162, p. 433-40, 2005.

LACAN, J. Conferência: o lugar da psicanálise na medicina. 1966. Disponível em: <http:// pt.scribd.com/doc/167248091/Lacan-O-Lugar-da-Psicanalise-na-Medicina>. Acesso em: 29 abr. 2013.

MALDINEY, H. Penser l'homme et la folie. Grenoble: Millon, 1991.

NATIONAL INSTITUTE OF MENTAL HEALTH. Disponível em: <www.nimh.nih. gov/research-priorities/rdoc/index.shtml> 
PEREIRA, M.E.C. Minkowski ou a psicopatologia como psicologia do pathos humano.

Revista Latinoamericana de Psicopatologia Fundamental, v. III, n. 4, p. 153-155, dez. 2000.

PESSOTTI, I. A loucura e as épocas. Rio de Janeiro: Editora 34, 1994.

STANGHELLINI, G.; BROOME, M.R. Psychopathology as the basic science of psychiatry. The British Journal of Psychiatry, v. 205, p. 169-170, 2014.

SZASZ, T.S. The myth of mental illness. The America Psychologist, v. 15, p. 113-118, 1960.

VON WEIZSAECKER, V. Le cycle de la structure. Paris: Desclée de Brouwer, 1958.

WAKEFIELD, J.C. The concept of mental disorder. On the boundaries between biological facts and social values. The American Psychologist, v. 476, p. 3, p.373-388, 1992.

ZORZANELLI, R.; DALGALARRONDO, P.; BANZATO, C.E.M. O projeto Research Domain Criteria e o abandono da tradição psicopatológica. Revista Latinoamericana de Psicopatologia Fundamental, v. 17, n. 2, p. 328-341, 2014.

\section{Nota}

${ }^{1}$ Pode-se, igualmente, interrogar o que significa do ponto de vista da seleção natural uma disfunção dos mecanismos neurobiológicos subjacentes ao funcionamento mental. Dado que o elemento mais fundamental da seleção natural é a permanente emergência da variação da norma, elemento que permite a sobrevivência de alguns indivíduos estatisticamente anormais, porém mais bem adaptados às novas condições ambientais, em perpétua transformação. Levando-se essa perspectiva a suas consequências necessárias, o papel clínico da psiquiatria não seria o de restituir à "order" os comportamentos e funcionamentos mentais caídos em "disorder", mas garantir a sobrevivência enquanto tal do máximo de variações, única garantia de que a espécie poderia sobreviver a condiçôes ambientais em contínua modificação. 
The crisis of psychiatry based on the diagnosis and the future of clinical psychiatry: psychopathology, medical anthropology, and the subject of psychoanalysis

The progress of modern psychiatry in the paths of biomedicine has led to the impression that psychopathology, as a science of human suffering in its various dimensions, would have become obsolete. A psychiatric nosology built exclusively on biological and experimental bases would take its place, definitely founding psychiatry as a medical specialty in its own right. This paper examines the dilemmas of that project to the reduction of the psychopathology into nosology and point some clues by which psychoanalytic theory of the subject and its pathos could provide the anthropological basis for the foundation of a psychopathology able to sustain psychiatric clinical practice.

> Key words: psychopathology; psychiatric nosography; medical anthropology. 